\title{
The discourse bases of relativization: An investigation of young German and English-speaking children's comprehension of relative clauses
}

\author{
SILKE BRANDT,* EVAN KIDD, ELENA LIEVEN and \\ MICHAEL TOMASELLO
}

\section{Abstract}

In numerous comprehension studies, across different languages, children have performed worse on object relatives (e.g., the dog that the cat chased) than on subject relatives (e.g., the dog that chased the cat). One possible reason for this is that the test sentences did not exactly match the kinds of object relatives that children typically experience. Adults and children usually hear and produce object relatives with inanimate heads and pronominal subjects (e.g., the car that we bought last year) (cf. Kidd et al. 2007). We tested young 3-year old German- and English-speaking children with a referential selection task. Children from both language groups performed best in the condition where the experimenter described inanimate referents with object relatives that contained pronominal subjects (e.g., Can you give me the sweater that he bought?). Importantly, when the object relatives met the constraints identified in spoken discourse, children understood them as well as subject relatives, or even better. These results speak against a purely structural explanation for children's difficulty with object relatives as observed in previous studies, but rather support the usage-based account, according to which discourse function and experience with language shape the representation of linguistic structures.

Keywords: object relative clauses; cross-linguistic acquisition; processing; discourse function; input frequencies.

* Correspondence address: Silke Brandt, Department of Developmental and Comparative Psychology, Max Planck Institute for Evolutionary Anthropology, Deutscher, Platz 6, 04103, Leipzig, Germany. E-mail:〈brandt@eva.mpg.de〉. Acknowledgements: We would like to thank Jessica Butcher for testing the English children for us and all children and their parents who participated in the study in Manchester and Leipzig. Furthermore, we would like to thank Holger Diessel and one anonymous reviewer for very helpful comments on an earlier draft of this paper. 


\section{Introduction}

The processing and comprehension of relative clauses (henceforth RCs) has been investigated in numerous experiments in the fields of adult psycholinguistics and language acquisition. Until recently, the common outcome of these studies was that both adults and children were better or faster at processing and comprehending subject relatives, such as (1), than object relatives, such as (2) (e.g., de Villiers et al. 1979; Frazier and Clifton 1989; Friedmann and Novogrodsky 2004; Gordon et al. 2001; Tavakolian 1981).

(1) the dog that chased the cat
(2) the dog that the cat chased

Notwithstanding a wide variety of explanations for children's difficulty with object relatives that assume that children employ processing mechanisms not found in adults (see Clancy et al. 1986; Kidd and Bavin 2002), most accounts given in the psycholinguistic literature explain the objectsubject asymmetry by appealing to differences in syntactic complexity between object and subject relatives. Explanations of this type are purely formal. They suggest that phenomena such as movement result in greater distances between fillers, or head NPs, (the dog in (1) and (2) above) and gaps (indicated by underscores in (1) and (2)) in object relatives than in subject relatives. Hence, the human parser needs to keep track of the filler for a longer period of time and over more constituents when processing object relatives. In the case of subject relatives, the gap is closer to the filler and can thus be filled immediately, leading to lower processing and memory costs (e.g., Gibson 1998). Similarly, the active-filler hypothesis (Frazier and Clifton 1989) states that object relatives are initially misanalyzed as subject relatives and, thus, result in higher processing costs because the parser must recover from the wrong analysis. To explain children's difficulties with object relatives, it has also been suggested that they have more difficulty with structures that involve movement per se (e.g., Friedmann and Novogrodsky 2004) and, unlike adults, sometimes employ a non-movement strategy in their RC production (Goodluck et al. 2006).

Independent of any linguistic theory that involves movement and gaps, it has been suggested that, in certain languages, subject relatives are easier to comprehend and process because they have canonical word order; the order of subject and object or agent and patient in subject relatives resembles that found in simple transitive sentences (Bever 1970; Diessel and Tomasello 2005). For example, in SVO languages with head-initial RCs, such as German or English, children will arrive at the right interpretation of the RC when they assign the first NP the agent role and the second NP 
the patient role, as in simple transitive sentences (see also de Villiers et al. 1979). In object relatives in these languages, however, the agent-patient order found in (canonical) simple transitives is reversed; the patient expressed by the head NP precedes the agent expressed in the following RC. The assumption that relatives with canonical word order are easier to comprehend is supported by the fact that there are actually languages, such as Chinese, in which object relatives are easier to process than subject relatives because their surface structure is more similar to simple sentences (Hsiao and Gibson 2003). Like English or German, Chinese is also a SVO language, but it has head-final RCs (i.e., the RC comes before the head NP). Hence, in Chinese object relatives, the agent expressed in the relative clause precedes the patient expressed by the head NP, whereas in Chinese subject relatives the patient expressed in the relative clause precedes the agent expressed by the head NP. In short, whereas English or German subject relative constructions have canonical agent-patient word orders, Chinese subject relative constructions have non-canonical patientagent word orders. Consistent with the idea that children's processing of $\mathrm{RCs}$ is eased by the canonical word order patterns of their language, a recent study by Chan et al. (2007) showed that Cantonese-speaking children experienced less difficulty imitating object than subject relatives.

An alternative, more functional, explanation for why both children and adults experienced difficulty with object relatives in previous studies derives from the work of Fox and Thompson (1990). Looking at more than 400 RCs in spoken English discourse, they identified important discourse properties of subject and object relatives that were neglected in previous experimental studies. Subject relatives are mainly used to provide new information about and characterize inanimate and animate main-clause objects (e.g., I got something that's wild) or existential, mainly human, heads (e.g., there are over a hundred thousand people who are over a hundred years old $)^{1}$. These subject relatives are usually intransitive; they characterize or describe referents that have been situated in the ongoing discourse or linked to given discourse participants by the preceding main or copula clause.

On the other hand, object relatives are most often used to ground inanimate entities in discourse. They mainly occur with inanimate, nonhuman main-clause subjects whose referents are new in the discourse. By being explicitly related to given referents, the new inanimate entities are made relevant to the ongoing discourse (Fox and Thompson 1990: 300). The grounding is accomplished by linking the inanimate entities to given

1. All examples given in this paragraph are taken from Fox and Thompson (1990). 
discourse participants, expressed by pronominal $I$ or you, or other given referents in the immediate context, expressed by 3rd person pronouns. The corpus study showed that object relatives are overwhelmingly used with inanimate heads and pronominal RC subjects, as in the following example (Fox and Thompson 1990: 303):

\section{(3) the car that she borrowed had a low tire}

This distribution can be derived from two facts that are true for almost all sentences in a language: (1) subjects are topical; they refer to given, and generally animate, entities, which are encoded by pronouns (cf. Du Bois 1987), and (2) objects tend to be inanimate (cf. Mak et al. 2002, 2006).

Following the lexicalist multiple-constraints approach to language processing (e.g., MacDonald et al. 1994), according to which sentence processing is also influenced by semantic, contextual, and frequency information, and not just by formal and structural sentence properties, one can assume that, in previous experimental studies, object relatives caused difficulty because the test sentences did not satisfy the constraints found for object relatives in natural speech, as identified by Fox and Thompson (1990). This assumption can also be derived from the usage-based approach and cognitive linguistics, according to which discourse function and linguistic experience shape our representation of grammatical structures (e.g., Bybee 2006; Langacker 2000; Tomasello 2003). We can thus hypothesize that the difficulties with object relatives observed in previous studies were, at least in part, due to the fact that the test sentences did not match the object relatives that children and adults had experienced in their input and own productions. Instead, children and adults were asked to act out or read object relatives with animate heads and full-NP subjects, such as (4) (Corrêa 1995):

(4) the chicken that the pig pushed jumped over the sheep

More recent studies in adult psycholinguistics have shown that high processing costs associated with object relatives can be reduced or eliminated when the clauses are attached to inanimate heads (Mak et al. 2002, 2006; Traxler et al. 2002, 2005) or when they contain pronominal subjects (Gordon et al. 2001; Reali and Christiansen 2007a; Warren and Gibson 2002, 2005). The authors of these studies offered several explanations for these results. For example, relying on frequency information, the parser can expect an object relative after hearing an inanimate NP followed by a relativizer. Inanimate entities are also good candidates for patients or objects in general (Mak et al. 2002, 2006). In addition, having a pronominal subject expressing old information within the RC causes less process- 
ing cost than having a full-NP subject (Warren and Gibson 2002). Pronouns refer to given referents whose representation is already activated, whereas lexical NPs refer to new referents whose representation needs to be activated when they are encountered (e.g., Chafe 1994). The processing of object relatives with pronominal subjects thus involves less cost for activating referent representations. Moreover, just as inanimate entities are very likely to be objects, pronouns are very likely to be subjects (cf. Du Bois 1987). Again, based on discourse function and following frequency distributions in previous linguistic experience, the parser can expect an object relative after hearing a relativizer followed by a pronoun (Reali and Christiansen 2007a). For a more detailed summary of the results and their interpretations see Kidd et al. (2007).

Do children show the same sensitivity to these constraints in their own RC production? Two corpus studies suggest that English- and Germanspeaking children's object relatives follow the same discourse constraints and frequency distributions that were observed for English-speaking adults. Focusing on animacy constraints in two English spoken child corpora, Diessel (2007) showed that more than 75 percent of all inanimate RC heads were followed by non-subject relatives. More specifically, about 90 percent of all object relatives produced by the children between the age of 2;3 and 5;2 followed a head NP denoting a non-human referent. Similar results were reported by Kidd et al. (2007). Looking at spoken corpora from four English children and one German child between the age of 2;0 and 5;0, we found that both English- and German-speaking children used object relatives with inanimate heads 75 percent of the time. In addition, in both languages, at least 75 percent of the object relatives produced by the children had pronominal subjects. Thus, the same constraints found for RC production by adults seem to influence children's $\mathrm{RC}$ production.

In order also to test these constraints in an experimental setting, Kidd et al. (2007) asked 3- and 4-year old English and German children to imitate subject and object relatives with animate and inanimate heads as well as object relatives with pronominal and full-NP subjects. The children were tested on the following kinds of sentences:

(5) This is the boy that the girl teased at school yesterday. (obj_an_np)

(6) That is the dog that you stroked in the park yesterday. (obj_an_pro)

(7) Here is the food that the cat ate in the kitchen today. (obj_in_np)

(8) There is the book that you read in the front room last night. (obj_in_pro)

(9) Here is the lady that helped the girl at school today. (subj_an)

(10) Here is the plant that grew in the garden last summer. (subj_in) 
Following expectations derived from the distributions found in the naturalistic data, the children made fewer errors when repeating object relatives with inanimate heads (examples (7) and (8)) and/or pronominal subjects (examples (6) and (8)) than object relatives with animate heads (examples (5) and (6)) and full-NP subjects (examples (5) and (7)). The children did not have more problems repeating object relatives that followed the constraints found in natural language than repeating subject relatives. Children in both languages performed best when they were tested on object relatives that they most often say and hear, and the subject-object asymmetry reported in a great number of previous studies was eliminated with these prototypical object relatives. Therefore, contra to those early accounts of syntactic acquisition that attributed children's difficulties with object relatives to poor syntactic knowledge, Kidd et al. (2007) showed that, following usage-based approaches to language acquisition, their syntactic knowledge is considerable but closely tied to their linguistic experience.

However, given our sentence-repetition task, we cannot be completely sure that as well as testing production we were also testing RC comprehension, as has been the case in most of the previous studies on RC acquisition. Although there are studies suggesting that children's imitation behavior is good evidence for their grammatical competence (for an overview see Lust et al. 1996) and that sentence imitation involves sentence comprehension (Potter and Lombardi 1990, 1998; Sachs 1967), we cannot fully rule out that some of the children we tested were just mimicking the experimenter. Moreover, our imitation data does not necessarily show that children had fewer problems with object relatives containing pronominal subjects because these pronouns refer to given referents. Using pronominal subjects implies that the subjects were given and topical because that is how grammar encodes given referents, but the sentences were presented without any context that would really control which referents were topical and given and which were new. If we assume that children's comprehension of object relatives is improved in pragmatically appropriate contexts, they should be better with object relatives that are used to relate new referents to given referents (cf. Fox and Thompson 1990).

To our knowledge, there are two comprehension studies that looked at animacy or pronominal subjects as factors influencing children's difficulty with object relatives. ${ }^{2}$ Controlling the number of animate vs. inanimate

2. Goodluck and Tavakolian (1982) also showed that the number of animate entities in subject relatives influences the ease of comprehension in children. 
entities in subject- and object-relative constructions, Corrêa (1995: 194) showed that "object focus sentences (...) appeared to be particularly affected by animacy". Portuguese-speaking children had fewer problems acting out object relatives with two animate referents and an inanimate head, such as (11), than object relatives with three animate referents including an animate head, such as (12):

(11) The sheep pushes the fence that the horse knocked down.

(12) The pig pushes the sheep that the horse knocked down.

In a comprehension and production study with Hebrew-speaking children, Arnon (forthcoming) showed that children better understood object relatives containing pronominal subjects than object relatives with fullNP subjects. However, we are not aware of any study that systematically tested children's comprehension of object relatives controlling for both factors and for the interaction between them. Therefore, we designed a referential-choice task that tested children's understanding of subjectand object relatives, controlling for animacy of the head NP and the discourse status of the subject in object relatives or the object in subject relatives. In contrast to the act-out method that was used in most studies on children's RC comprehension before (e.g., Corrêa 1995; Eisenberg 2002; Goodluck and Tavakolian 1982; Kidd and Bavin 2002; Sheldon 1974), the referential-choice task places minimal demands on the children. We were thus able to show RC comprehension in children much younger than in most previous studies, where successful comprehension is not typically evident until around 4 years.

Our predictions were that, like adults, children would show less difficulty comprehending object relatives that are consistent with the constraints identified from their own production and in their input than object relatives that do not meet these constraints. That is, we expected children to perform best when object relatives contained an inanimate head noun and a pronominal RC subject. Assuming that the acquisition of syntactic constructions is strongly driven by production and input frequencies, which, in turn, can be derived from their discourse functions (e.g., MacDonald 1999; Tomasello 2003), even young children should be sensitive to these constraints. Object relatives occur quite frequently in the input of English- and German-speaking children (Brandt et al. 2008; Diessel 2004). In fact, English-speaking children even hear more object than subject relatives (Diessel 2004). Thus, once children have to interpret object relatives that are similar to the ones they have experienced before, they should be able to comprehend them at least as well as subject relatives. This should be true for both English- and German-speaking 
children because children from both language groups hear and produce the same types of object relatives (cf. Kidd et al. 2007).

However, mainly due to the fact that the languages differ in how they mark semantic roles, we also expected some minor cross-linguistic differences. In English, only certain pronouns are case-marked, whereas in German, both pronouns and lexical nouns are case-marked. ${ }^{3}$ Previous studies have shown that English-speaking children overwhelmingly rely on word order to assign semantic roles, whereas German-speaking children also pay attention to case marking and animacy, and that children are unable to interpret sentences where two cues are put into conflict until they are quite old (e.g., Chan et al. 2009; Dittmar et al. 2008). It is thus likely that, when processing RCs, the German-speaking children are more sensitive to the constraint of animacy than the English-speaking children, and that they also have more difficulty with object relatives, where case marking and word order are put into conflict.

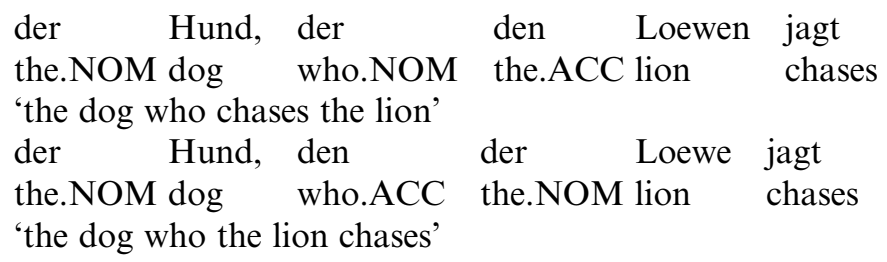

The examples demonstrate that in German subject relatives the subject of the relative clause expressed by the relative pronoun der 'who.NOM' is both marked nominative and precedes the object (see example (13)), as is the case in the vast majority of sentences in German. In object relatives, however, the subject expressed by the RC-internal NP der Loewe 'the.NOM lion' is marked nominative, but comes after the object (see (14)). In the English relatives (with two lexical NPs), on the other hand, the only cue for semantic role assignment is word order.

\section{Method}

\subsection{Participants}

Twenty-nine $(N=29)$ young 3-year old German-speaking children were recruited from nurseries in Leipzig. Five children were excluded because they showed a side bias (2) or they were fussy and did not finish the task (3). The final German sample consisted of twenty-four 3-year old children

3. It has to be noted though that only masculine nouns always display unambiguous case marking. 
(mean $=2 ; 11$, range: 2;9-3;1). All children were native monolingual speakers of German; none had any known language impairment.

Another twenty-four $(N=24)$ young 3-year old English-speaking children were recruited from a database of families at the Max Planck Child Study Centre, The University of Manchester. Four children were excluded because they showed a side bias (1) or they were fussy and did not finish the task (3). The final English sample consisted of twenty 3year olds (mean $=3 ; 0$, range: $2 ; 7-3 ; 4$ ). All children were native monolingual speakers of English; none had any known language impairment.

\subsection{Materials}

Twenty-four test sentences were constructed. The first manipulation was the NP relativized within the RC (subject- vs. object relatives). The second was the type of NP within the RC. Subject relatives had pronominal or full-NP objects, while object relatives had pronominal or full-NP subjects. We always used third person singular and case-marked pronouns he (in German er) and him (in German ihn). The referent of the third person pronoun was always the same toy doll, Peter, who was introduced at the beginning of the experimental session and who kept reappearing for all sentences containing pronouns. The referent of the pronoun can thus be considered given in the current study. Finally, object relatives had animate or inanimate head NPs. In order to only have plausible transitive RCs, subject relatives always had animate head NPs. These manipulations resulted in six conditions, as shown in Table 1.

We had four sentences per test condition (see appendix): 'subj' and 'obj' stand for subject and object RC; 'an' and 'in' stand for animate and inanimate head NP. Finally, 'np' stands for full-NP subject within object relatives and full-NP object within subject relatives, and 'pro' stands for pronominal subject within object relatives and pronominal

Table 1. Examples of test sentences for each condition

\begin{tabular}{lll}
\hline & Subject relative & Object relative \\
\hline $\begin{array}{l}\text { Animate head } \\
\text { full NP }\end{array}$ & $\begin{array}{l}\text { Can you give me the dog that } \\
\text { chased the lion? }\end{array}$ & $\begin{array}{l}\text { Can you give me the monkey that } \\
\text { the frog combed? }\end{array}$ \\
$\begin{array}{l}\text { Animate head } \\
\text { pronominal NP }\end{array}$ & $\begin{array}{l}\text { Can you give me the donkey } \\
\text { that just tickled him? }\end{array}$ & $\begin{array}{l}\text { Can you give me the donkey that } \\
\text { he just fed? }\end{array}$ \\
$\begin{array}{l}\text { Inanimate head } \\
\text { full NP }\end{array}$ & - & $\begin{array}{l}\text { Can you give me the cake that the } \\
\text { uncle stole? }\end{array}$ \\
Inanimate head & - & $\begin{array}{l}\text { Can you give me the ball that he } \\
\text { pronominal NP }\end{array}$
\end{tabular}


object within subject relatives. Therefore, the abbreviation obj-an-np refers to object RCs that had an animate head noun and a full lexical NP subject.

The test sentences were controlled for length in words and syllables. In both German and English, all sentences were 10 words in length. The sentences were matched for length by adding adverbials eben or gerade, which both mean just, to the German sentences with pronouns and by adding just to the English sentences with pronouns. In terms of syllables, the German sentences were slightly longer (12-14) than the English prompts (10-12), since German words tend to be longer than English words.

\subsection{Procedure}

The German children were tested in a quiet room in their nurseries. The English children were tested in a laboratory in the Max Planck Child Study Centre at the University of Manchester. All sessions were videotaped.

All animals (lion, tiger, bear, monkey, (tom) cat, frog, donkey, and dog), inanimate entities (pen, sweater, ball, and cake), and humans (uncle, dad, boy, grandpa, and Peter) that were used in the test sentences were present as small toys. All these nouns are masculine in German and are thus clearly case marked. The animals and inanimate entities served as referents for the RC head NPs; that is, the NPs that were modified by the RCs. We had two of each kind that could easily be distinguished by size, color, and/or shape. For example, we had a black and a brown (tom) cat, we had a tall brown monkey and a smaller black monkey, a red pen and a black pen, etc. At the beginning of each session, the experimenter presented all animals and inanimate entities in pairs to make these differences clear. For example, the experimenter put the two monkeys on the table and asked the child if the two looked alike or what distinguished them. The experimenter also presented a toy doll called Peter, the referent of the pronouns in the test sentences, and said that he was going to play a lot with the animals and objects.

In the warm-up phase the experimenter then put a pair of animals or inanimate objects (e.g., the black and the brown cat) on a paper disk, which was fixed in front of the child, and asked the child: can you give me the brown cat? The child was encouraged to put the chosen animal or object down a small toy slide. In order to give the children a reason to choose a referent the experimenter said that they all really liked to go down the slide, but that only one could go at a time, so the child and the experimenter had to choose who got to go. The referential-selection 
task was practiced four times. All children understood the task and participated.

The test items were then presented as in the following example:

\section{Two background scenes:}

The experimenter presented one of the two lions and a dog and said: Look, the dog is chasing this lion. Then she acted out this first background scene. She described and acted out the first background scene again and put the first lion on one side of the disk in front of the child. Then she presented the second lion with the same dog and said: Look, the dog is pushing this lion. This second background scene was also described and acted out twice before the second lion was put on the other side of the disk by the experimenter.

Before target sentences with pronominal subjects or objects within the $\mathrm{RC}$, the experimenter presented Peter and said something along the lines of: Look, here's Peter again. Let's see what he's doing now! The background scenes were then also described with pronouns (e.g., He's washing this frog. or This frog is combing him.):

\section{Distracter scene:}

Before the referential-choice task, the experimenter described and acted out a distracter scene with the animal or human that was not the head of the test RC: Look, now the dog goes swimming. Then the dog was placed between the two lions on the disc.

\section{RC test sentence:}

Finally, the experimenter asked the child: Can you give me the lion that the dog chased?

The introduction of each referent and their position before the test sentence was counterbalanced within subjects. That is, half the time the target referent was introduced in the first background scene and the other half of the time it was introduced in the second background scene. Similarly, half the time the target appeared on the left side of the disk and the other half of the time it appeared on the right side. In addition, the order of presentation was pseudo-randomized: test sentences from the same condition did not appear more than twice in a row. We used four different orders.

The verbs and actions described were: wash, comb, tickle, feed, kick, bite, push, and chase for animate objects and touch, move, bake, steal, knit, throw, buy, and kick for inanimate objects, with the German equivalents (see appendix). 


\subsection{Scoring}

The chosen referent was either put on the slide by the child or by the experimenter after the child had clearly pointed to it or picked it up herself. If the child did not pick up a referent or unambiguously pointed to a referent, the experimenter repeated the test sentence once. After one repetition the experimenter continued with the next item. We coded whether the child chose the 'correct referent' (e.g., the correct lion), whether she chose the 'incorrect token' of the head NP, or whether she did not make a choice (e.g., by picking up both lions or by picking up none). We also coded whether the child chose the 'incorrect NP referent' (e.g., the child chose the dog after hearing Can you give me the lion that the dog chased?). Some children also picked up both the correct agent and patient (e.g., the correct lion together with the dog). This was coded as 'ambiguous'.

Before presenting the results, we would like to note that our procedure is different from that of previous RC comprehension studies (e.g., Corrêa 1995; Eisenberg 2002; Goodluck and Tavakolian 1982; Kidd and Bavin 2002; Sheldon 1974) where children were asked to act out RC constructions containing two clauses, such as the chicken that the pig pushed jumped over the sheep (Corrêa 1995). In order to succeed in this act-out task, children have to understand agent-patient relations expressed in the sentence, i.e., they have to understand 'who is doing to what to whom'. In the referential-selection task we used for the current study, the children have to match agents or patients with verbs or actions. For example, what distinguishes the black and the brown cat is that one fed the donkey or was fed by the donkey while the other tickled the donkey or was tickled by the donkey. Based on the link between a certain cat and a certain action, the child can choose the correct referent after hearing give me the cat that the donkey tickled without necessarily fully understanding 'who did what to whom'. However, above chance performance $(>33 \%$ correct) suggests that, in the current study, children are capable of parsing the $\mathrm{RC}$ as a restrictive noun modifier; they interpret the second predicate as being about the referent of the antecedent NP. In the current study, children are presumably also able to comprehend relative-clause constructions at a relatively early age because the test sentences contain an imperative clause concerning the interaction between the experimenter and the child and a relative clause to describe a referent from the preceding story that the child heard and watched. In other words, our test sentences were easier than the ones used in previous studies because they did not contain two full propositions on the same speech-act level.

We chose to use this task because it places minimal demands on the children. The act-out task had been criticized before for being too de- 
manding and not showing children's full grammatical competence (e.g., Hirsh-Pasek and Golinkoff 1996). The referential-choice task allows us to test children who are quite young. Moreover, it allows us to use RCs in an experimental setting for the same purpose for which they are used in real life: restrictive relatives are used to identify things (e.g., Givón 1993; Lehmann 1984) and link new entities to given entities (Fox and Thompson 1990). RC constructions like the ones that were used in the act-out tasks in previous studies mentioned above, on the other hand, are rarely used in real life (cf. Diessel 2004).

\section{Results}

The correct responses from each child in each condition were divided by the total number of items in each condition. This resulted in a proportional value for each subject in each condition, which was then transformed using an arcsine transformation. Overall, the children performed above chance $(33 \%)$ in every condition with one exception: the German children did not differ from chance when object relatives contained an animate head noun and a lexical-NP subject within the RC. This suggests that the children from both language groups possessed sufficient knowledge to parse each sentence type in almost every instance. The Germanspeaking children's data are discussed first, followed by the Englishspeaking children's data.

\subsection{German-speaking children's data}

The mean proportion correct and standard errors $(+/-1 \mathrm{SE})$ for each condition for the German-speaking children is presented in Figure 1.

Figure 1 shows that, overall, the German-speaking children did not perform better on subject relatives than on object relatives. They performed best in the object relative conditions where the sentence contained an inanimate head noun, followed by subject relatives, and worst on the object relatives that contained an animate head.

We report two analyses. The first concerns whether the children are sensitive to the same constraints on object RC formation in comprehension as they are in production, as identified by Kidd et al. (2007). The second concerns a direct comparison between subject and object relatives.

A 2 (Animacy: animate versus inanimate) by 2 ( $R C$ subject type: lexical NP versus pronominal NP) repeated measures ANOVA was conducted on the object relatives. A significant main effect for animacy showed that the children performed better on sentences containing inanimate head nouns than those that contained animate heads $(F(1,23)=$ 


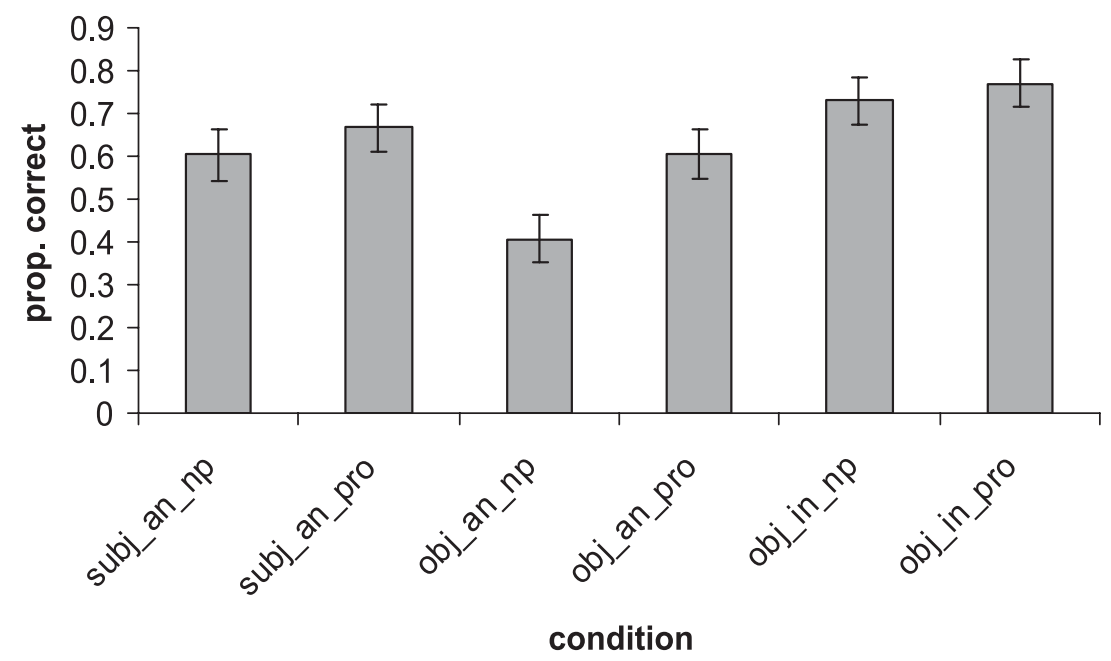

Figure 1. Mean proportion correct (and SES) for each condition for the German-speaking children

19.75, $p<0.001$, partial $\eta^{2}=0.462$ ). A significant main effect for $\mathrm{RC}$ subject type showed that the children performed better on those sentences that contained pronominal $\mathrm{RC}$ subjects than on those that contained lexical-NP subjects $\left(F(1,23)=5.03, p=0.035\right.$, partial $\left.\eta^{2}=0.179\right)$. The animacy by RC subject type interaction was not significant $(F(1,23)=$ $2.28, p=0.144$, partial $\eta^{2}=0.09$ ).

We next compared the German children's performance on the subject relatives relative to their performance on the object relatives. We compared only those sentences that contained animate head NPs, since no subject relatives contained inanimate head NPs. A 2 (Structure: subject versus object RC) by 2 (NP type: lexical NP versus pronominal NP) ANOVA was conducted. There was a main effect of structure type showing that subject relatives with animate heads were processed better overall than object relatives with animate heads $(F(1,23)=4.97, p=0.036$, partial $\left.\eta^{2}=0.178\right)$. The main effect for NP type was also significant, showing that sentences containing pronouns were easier to process than those that contained two full lexical NPs in the $\mathrm{RC}(F(1,23)=6.09, p=0.021$, partial $\left.\eta^{2}=0.209\right)$. The interaction was not significant $(F(1,23)=2.19$, $p=0.152$, partial $\left.\eta^{2}=0.087\right){ }^{4}$

4. This result could be taken to suggest that subject RCs are easier for children to process when the test sentences are equated on the type of NPs that occur in each sentence. However, this conclusion is not warranted, and is addressed in the discussion. 


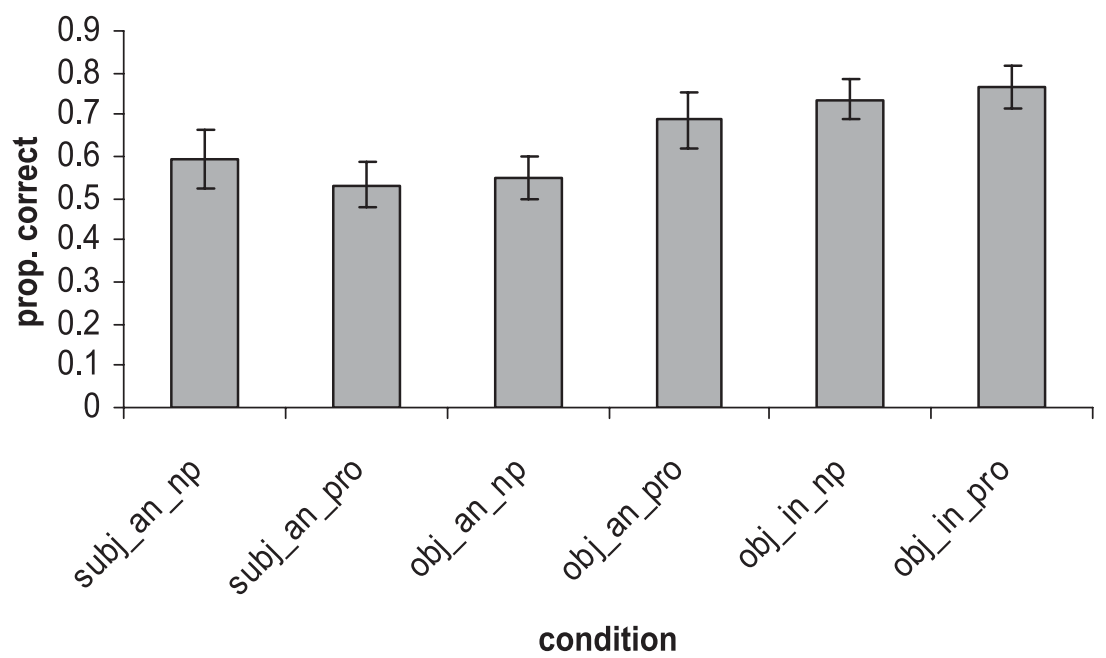

Figure 2. Mean proportion correct (and SEs) for each condition for the English-speaking children

\subsection{English-speaking children's data}

The mean proportion correct and standard errors $(+/-1 \mathrm{SE})$ for each condition for the English-speaking children is presented in Figure 2.

Figure 2 shows that, like the German-speaking children, the Englishspeaking children performed best on the object relatives that contained inanimate head NPs. Their performance on the sentences that contained animate head nouns was fairly uniform, with the exception of the obj_an_pro condition, where their performance was better.

A 2 (Animacy: animate versus inanimate) by 2 ( $R C$ subject type: lexical NP versus pronominal NP) repeated measures ANOVA was conducted on the object relatives. Although the children performed better numerically on object RCs that contained inanimate heads, the main effect for animacy was not significant $\left(F(1,19)=2.86, p=0.11\right.$, partial $\eta^{2}=$ $0.131)$. There was a significant main effect of RC subject type, showing that children performed better on sentences that contained pronominal RC subjects $\left(F(1,19)=4.93, p=0.039\right.$, partial $\left.\eta^{2}=0.206\right)$. The animacy by RC subject type interaction was not significant $(F(1,19)=2.1$, $p=0.163$, partial $\eta^{2}=0.10$ ).

We next compared the English-speaking children's performance on the subject relatives relative to their performance on the object relatives. As for the German-speaking children, we only compared those sentences that contained animate head NPs, since no subject relatives contained 
inanimate head NPs. A 2 (Structure: subject versus object RC) by 2 (NP type: full lexical NP versus pronominal NP) repeated measures ANOVA was conducted. The analysis revealed a significant structure by NP-type interaction $\left(F(1,19)=6.81, p=0.017\right.$, partial $\left.\eta^{2}=0.264\right)$. Post hoc ttests revealed that this interaction was driven by the fact that the children's performance did not differ between the two varieties of subject relatives $(t(19)=0.581, p=0.568)$, but they performed significantly better on object relatives that contained a pronominal $\mathrm{RC}$ subject than those that contained a full lexical NP RC subject $(t(19)=2.58, p=0.01)$.

\subsection{Comparing the German- and English-speaking children}

We next compared the two language populations directly to investigate any possible between-language differences. We first compared the children's performance on the object relatives. A 2 (Animacy: animate versus inanimate) by 2 (RC subject type: lexical NP versus pronominal NP) by 2 (Language: German versus English) repeated measures ANOVA revealed a significant main effect for animacy $(F(1,42)=17.26, p<0.001$, partial $\eta^{2}=0.291$ ), showing that children performed better on object relatives that contained inanimate heads. There was also a significant main effect for RC subject type $\left(F(1,42)=9.20, p=0.004\right.$, partial $\left.\eta^{2}=0.18\right)$, showing that, overall, the children parsed object relatives that contained a pronominal RC subject better than those that contained lexical NPs as subjects. The animacy by RC subject interaction was significant $\left(F(1,42)=4.33, p=0.044\right.$, partial $\left.\eta^{2}=0.093\right)$. Post hoc t-tests revealed that this interaction was driven by the fact that RC subject type only had an effect on the children's processing when the head noun was animate $(t(43)=4.05, p<0.001)$, but not when the head noun was inanimate $(t(43)=0.83, p=0.41)$. The main effect of language type was not significant $(F<1)$, and nor were there any significant interactions that included language as a variable (all $F$ s $<2.5$ ).

We next compared the children's performance on the subject relatives relative to their performance on the object relatives. A 2 (Structure: subject versus object RC) by 2 (NP type: full lexical NP versus pronominal $\mathrm{NP}$ ) by 2 (Language: German versus English) repeated measures ANOVA was conducted. The main effect of NP type was significant $\left(F(1,42)=6.14, p=0.017\right.$, partial $\left.\eta^{2}=0.128\right)$, showing that, overall, children processed the sentences containing pronouns better than those with two full lexical NPs. This result was subsumed by a significant structure by NP-type interaction $\left(F(1,42)=8.04, p=0.007\right.$, partial $\eta^{2}=$ 0.161 ). Post hoc t-tests showed that although NP type did not affect chil- 
dren's processing of subject relatives $(t(43)=0.35, p=0.728)$, it did significantly affect their processing of object relatives $(t(43)=4.05, p<0.001)$.

Finally, the structure by language interaction approached significance $\left(F(1,42)=4.02, p=0.051\right.$, partial $\left.\eta^{2}=0.087\right)$. This interaction was driven by the fact that, from the individual analyses of each language, the German children found the subject relatives easier than the object relatives overall (i.e., averaging across conditions), but the English children had no such preference.

\subsection{Error analyses}

As previously noted, the children performed above chance in the majority of conditions, yielding an average of 64 percent correct across the two languages $($ German $=63 \%$, English $=65 \%$ ). However, the children also made two consistent error types: (i) trials where they chose the incorrect token of the head referent, and (ii) trials where they chose the incorrect NP within the relative clause (e.g., choosing the donkey for the sentence give me the cat that the donkey tickled). The first category was by far the most frequent error type in both groups' data, accounting for $24.7 \%$ of the German children's total responses and 31.9\% of the English children's total responses. Figure 3 shows the distribution of children's errors when they chose the incorrect token of the head referent by language group and condition.

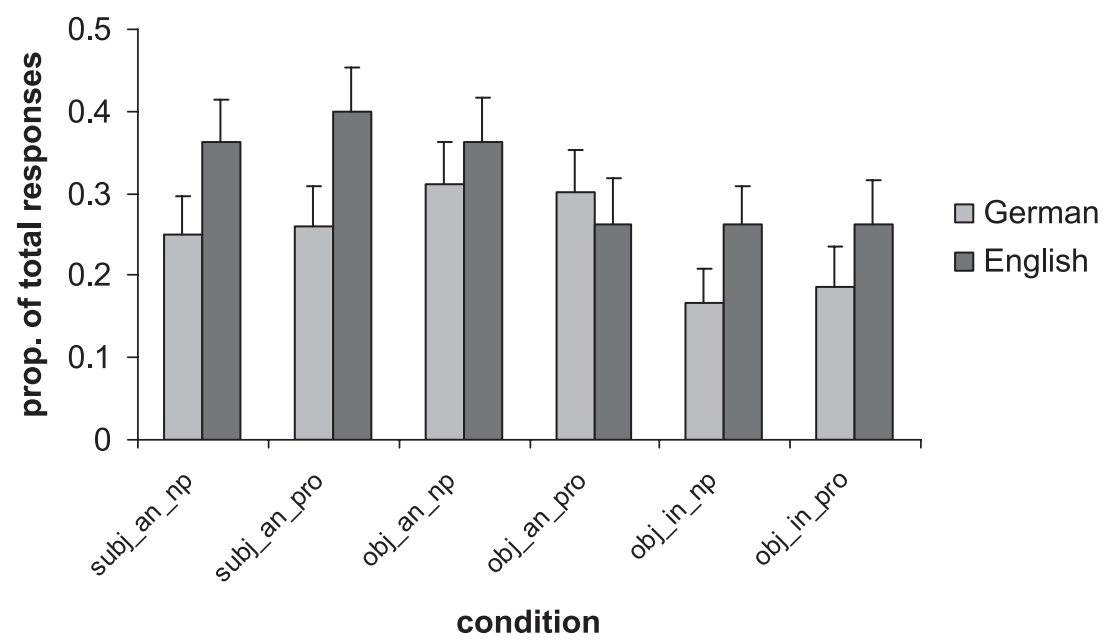

Figure 3. Mean proportion of errors (and SEs) where children chose the incorrect token of the head referent by condition and language 
There were two results to note for this error category. First, the English-speaking children made more of this error type than the German-speaking children when tested on subject relatives $(F(1,42)=$ 4.81, $p=0.034$, partial $\eta^{2}=0.103$ ), and, with respect to object relatives, the children made more of this error type overall when the test sentence contained an animate head noun $(F(1,42)=4.4, p=0.042$, partial $\left.\eta^{2}=0.095\right)$, although when each language was analyzed separately the effect was only significant for the German-speaking children $(F(1,23)=$ 4.73, $p=0.04$, partial $\eta^{2}=0.171$, English-speaking children $F<1$ ).

The second error type, where children chose the incorrect NP referent within the relative clause, accounted for $10.6 \%$ of the German children's total responses, and 3.3\% of the English children's total responses. Figure 4 shows the distribution of children's errors when they chose the incorrect NP referent by language group and condition.

Overall, the German-speaking children made this error significantly more often than did the English-speaking children $(F(1,42)=7.82$, $p=0.008$, partial $\eta^{2}=0.157$ ). The children's error types did not vary according to structure type; however, for object relatives this error type was predicted by the animacy of the head and the discourse status of the RC subject. For the German-speaking children, a 2 (Animacy: animate versus inanimate) by 2 (RC subject type: lexical NP versus pronominal NP) repeated measures ANOVA revealed a significant main effect for animacy $\left(F(1,23)=17.32, p<0.001\right.$, partial $\left.\eta^{2}=0.43\right)$, showing that this error



Figure 4. Mean proportion of errors (and SEs) where children chose the incorrect NP referent by condition and language 
type occurred significantly more often when the test sentences contained animate heads than when they contained inanimate heads. A significant main effect for RC subject type showed that this error occurred significantly more often when the test sentence contained a lexical NP RC subject than when it contained a pronominal $\mathrm{RC}$ subject $(F(1,23)=8.64$, $p=0.007$, partial $\left.\eta^{2}=0.273\right)$. The animacy by $\mathrm{RC}$ subject interaction approached significance $\left(F(1,23)=3.62, p=0.07\right.$, partial $\left.\eta^{2}=0.136\right)$.

Since the English-speaking children did not make this error for object relative sentences that contained inanimate head nouns, parametric statistics were not appropriate. Therefore, two Wilcoxon signed ranked tests were conducted, one comparing the children's performance on object relatives containing animate and inanimate heads, collapsing for RC subject type, and another comparing object relatives containing lexical-NP and pronominal RC subjects, collapsing for the animacy of the head referent. The results showed that the children made more of this error type when sentences contained an animate head noun $(Z=2.04, p=0.02)$, and when sentences contained a lexical NP RC subject $(Z=1.73, p=0.042)$.

\section{Discussion}

The results from Kidd et al. (2007) suggested that children are sensitive to the same constraints on object-relative production as adults when they have to imitate these sentences. The current study shows that these constraints can also be observed in comprehension. German- and Englishspeaking 3-year-old children showed better comprehension of object relatives with inanimate heads and pronominal subjects than object relatives with animate heads and full-NP subjects. Both factors, the animacy of the head NP and subject type within the RC, had a significant effect on the German children's performance. The English-speaking children performed significantly better on object relatives with pronominal RC subjects. They also showed better performance on object relatives with inanimate heads, but the effect did not reach significance. This finding is in accordance with studies on German- and English-speaking children's and adults' interpretation of simple transitives that found that Germans are more likely to pay attention to both word order and animacy, whereas English subjects overwhelmingly rely on word order (e.g., Bates and MacWhinney 1989; Chan et al. 2009). However, the English-speaking children also showed some sensitivity to the animacy constraint, as they made significantly more referent selection errors when object relatives contained animate head NPs.

When we analyzed the English- and German-speaking children's data together, we did not find a significant main effect for language or any 
significant interactions of the linguistic factors with language. Children from both language groups performed best on object relatives with inanimate heads and pronominal subjects. However, focusing on RCs with animate heads, the German-speaking children, but not the English children, showed a preference for subject relatives, which showed up in an interaction between language and structure that approached significance. This might be explained by frequency distributions in the children's input. While object relatives were found to be more frequent than subject relatives in the input of an English-speaking child (Diessel 2004), the analysis of German input data showed subject relatives to be more frequent than object relatives (Brandt et al. 2008). Whether this cross-linguistic difference in distribution would also be found in larger databases is perhaps questionable. A second, more probable explanation for the German children's difficulty with object relatives with animate heads is that these sentences place an extra heavy burden on their processing system. Note that, despite the fact that German has variable word order, in most sentences the subject precedes the object. In object relatives, however, the object precedes the subject. German children have been found to be sensitive to animacy, word order, and case marking as cues for semantic role assignment (e.g., Chan et al. 2009; Dittmar et al. 2008), and, in the case of object relatives with animate heads, two relevant cues (i.e., animacy and word order) point to the head NP as the agent. When the children encounter the case-marked relative pronoun den 'who.ACC', however, they have to revise their initial analysis. English-speaking children, on the other hand, presumably only pay attention to one cue: word order. They are thus more likely to wait to hear the $\mathrm{RC}$ verb before they start with semantic role assignment and the analysis of the RC structure. In this case, no reanalysis is necessary.

Language also had an impact on the children's error types. An error type that was more frequent with the German-speaking than the English-speaking children was choosing the incorrect NP referent; that is, not the head noun. This occurred in both subject and object relatives. Since these children are young, and the German children presumably pay attention to animacy, case marking, as well as word order when these cues do not always support each other, it is possible that they chose the most recently mentioned referent when their processing systems were over stretched. As just mentioned, the relative pronoun following the head NP is case marked and gives information about the role of the head NP in the following RC and the overall structure of the RC. Case marking as a cue to thematic role assignment is $100 \%$ reliable in German, but the morphological paradigm is quite complex. Most importantly, there is not a one-to-one mapping between form and function. For exam- 
ple, the form der can stand for masculine nominative, feminine dative, or feminine genitive. The determiners that carry case marking are also marked for gender and number. Previous studies have shown that the acquisition of the German determiner paradigm is a gradual process (e.g., Clahsen 1984; Szagun 2004). The processing of the case marking cue is costly for young German children, especially when it is not supported by word order or animacy constraints (cf. Dittmar et al. in 2008). Moreover, German relative pronouns have the same form as definite articles, and in our test sentences these two items occur right after one another as den der (who.ACC the.NOM) in object relatives or der den (who.NOM the.ACC) in subject relatives, which further complicates the processing of case marking and the syntactic structure for the German children. Although some pronouns in English are also marked for case, English children have been found to almost exclusively pay attention to word order for the purpose of semantic role assignment and processing of linguistic structures (e.g., Chan et al. 2009).

Another error type was more frequent in the English data: the Englishspeaking children were more likely than the German-speaking children to choose the incorrect token of the head NP. In other words, the Englishspeaking children had more problems matching the $\mathrm{RC}$ verb with the right referent. We can only give a speculative answer to why this might be the case. In the vast majority of sentences that English-speaking children hear, the lexical verb is placed close to its core arguments. In a great number of sentences in the input of German-speaking children (e.g., sentences in perfect tense or sentences with any kind of auxiliaries), however, the lexical verb is sentence-final, and there can be a number of constituents between the lexical verb and its core arguments. For example, the German equivalent of a simple transitive, such as the lion has pushed the dog in the garden would have the word order: the lion - has - the dog-in the garden-pushed. German-speaking children therefore have greater experience with matching lexical verbs with their core arguments even when they are separated by a number of constituents.

Before we move on to a more general discussion of the results, it is worth mentioning that the English data and the analysis across languages revealed an interaction between NP type and structure. That is, the processing of object relatives is eased with pronominal subjects within the RC, whereas the processing of subject relatives is not affected by whether the object within the RC is expressed by a pronoun or a lexical NP. Hence, it is not the number of lexical NPs vs. pronominal NPs per se, which affects processing of RCs (cf. Warren and Gibson 2002), but the pragmatically appropriate use of lexical NPs vs. pronominal NPs. Subjects are topical and expressed by pronouns, while objects tend to encode new referents, 
which tend to be expressed by lexical NPs. When these form-function mappings are used appropriately in object RCs, processing and comprehension can be improved in an experimental setting.

However, we should also note that the subject relatives that the children were tested on did not exactly match the kinds of subject relatives that young English- and German-speaking children most frequently use in their spontaneous speech. Early in development, before the age of 3;0, the majority of both German and English children's subject relatives were found to be intransitive (Brandt et al. 2008; Diessel and Tomasello 2000), and in our previous sentence-repetition study, German-speaking children had less difficulty with intransitive subject relatives than with transitive subject relatives, when they were attached to inanimate head NPs. However, the German children's performance on intransitive subject relatives was not better than their performance on (transitive) object relatives with pronominal subjects. Moreover, the English children actually performed better on transitive subject relatives than on intransitive subject relatives with inanimate head NPs (Kidd et al. 2007). Whether children would comprehend intransitive subject relatives with inanimate heads better than (transitive) object relatives with inanimate head NPs and/or pronominal subjects is a topic for further research. Furthermore, based on the data from the current study, we cannot be sure whether the children would have performed better on the subject relatives if they had contained inanimate objects. In the current study, the subject relatives contained animate objects, half of them even expressed by pronouns, which violates the assumption that referents in the object position tend to be new and inanimate (cf. Du Bois 1987; Mak et al. 2002). In fact, it might be surprising that we did not find an effect of NP type for the subject RCs. Since objects tend to express new referents encoded by lexical NPs, we should expect the children to better comprehend subject relatives with lexical-NP objects than subject relatives with pronominal objects. However, the tendency for objects to express new referents encoded by lexical NPs is not as strong as the tendency for transitive subjects to express given referents encoded by non-lexical NPs. Whereas objects are found to be expressed by both lexical NPs or pronouns, transitive subjects are overwhelmingly expressed by pronouns or non-overt argument forms (e.g., Du Bois, 1987). Thus, it makes sense that the processing of transitive clauses with pronominal objects, as opposed to transitive clauses with full-NP objects, is not as hard and unexpected as the processing of transitive clauses with full-NP subjects, as opposed to transitive clauses with pronominal subjects.

The focus of the current study was on children's comprehension of object relatives, and our results speak against a purely structural explana- 
tion of children's and adults' difficulties with these sentences observed in previous studies. The current findings cannot be explained by different gap positions in subject and object relatives (e.g., Frazier and Clifton 1989; Friedmann and Novogrodsky 2004), nor can they be fully explained by different subject-object or agent-patient orderings in subjectand object relatives (e.g., Bever 1970; Diessel and Tomasello 2005). Instead, we suggest that the difficulties with object relatives reported in previous studies were due to the fact that the test sentences did not match the object relatives that children and adults had experienced before. Our results can be best explained within the usage-based framework (e.g., Bybee 2006; Langacker 2000; Tomasello 2003), which claims that linguistic structures and their representations emerge out of and are shaped by usage events, which, in turn, depend on the specific functions of these structures (see also MacDonald 1999).

The corpus studies on object-relative usage (e.g., Fox and Thompson 1990; Kidd et al. 2007; Reali and Christiansen 2007a, 2007b; Roland et al. 2007) showed that both adults and children most often produce object relatives with inanimate head NPs and pronominal subjects. Object relatives with animate head NPs and full-NP subjects are rare in spontaneous speech. Speakers' preference for producing object relatives with inanimate head NPs and pronominal subjects can be derived from two basic facts that are also true for constructions other than object relatives: objects tend to be inanimate (e.g., Mak et al. 2002, 2006) and subjects are often expressed by pronouns (e.g., Du Bois 1987). Furthermore, object relatives serve a specific discourse function, which leads to their form. As first observed by Fox and Thompson (1990), object relatives are used to ground new, inanimate referents in discourse. New inanimate referents are made relevant by linking them to given discourse participants, which are expressed by 1 st or 2 nd person pronouns. We suggest that these basic discourse facts lead to the usage patterns concerning object relatives, and that children's repeated experience with this construction type in specific discourse contexts shapes their subsequent representations and parsing of object relatives.

One aim of the current study was to create a discourse context that is associated with the use of object relatives. One reoccurring character (Peter) was referred to with a pronoun to mark him as topical and given, and sometimes some fairly new inanimate entities were linked to Peter with an object relative (e.g., give me the ball that he just kicked). Both English and German children performed best in this appropriate discourse context. At this point, we are not able to tell whether children performed best in this condition because the discourse context was appropriate or because the object relatives used in this context had the form that 
they most frequently have in spontaneous speech. Further research will have to show how the factors of discourse context, pragmatic function, and frequency influence the representation of syntactic constructions and whether these factors work together or independently.

According to the usage-based approach, syntactic constructions are form-meaning pairings, which can be represented at different levels of abstraction (e.g., Bybee 2006; Goldberg 1995; Langacker 2000; Tomasello 2003). For example, a sentence such as the lion kicked the ball can be represented as an abstract transitive construction, requiring a subject, verb, and a direct object, or as an instance of a more item-specific construction, requiring a kicker, kick, and a kickee. In between these two extremes it is possible to imagine a semi-abstract, or prototypical, representation of a construction requiring an animate NP, a causative verb, and an inanimate NP. Abstraction is most likely to be achieved by analogy; the level of abstraction will be influenced and changed by linguistic experience and frequency of exposure. If an item-specific construction is used and heard in the exact same form over and over again, it will be represented at a very item-specific level (cf. Bybee 2006). If there is great variation among the form and meaning of NPs and verbs used and heard with this construction, the sentences matching this construction will be represented at a more abstract level. If there are common features among the NPs and verbs that are frequently used in this construction, these features will also be part of the representation. However, for analogy and abstraction to happen in the first place, the child or speaker needs to discover a commonality between the utterances to be compared. One obvious commonality between specific syntactic constructions is that they are used in similar contexts and serve similar functions. Since the most common function of object relatives is to ground new, inanimate referents into discourse, their form will usually consist of inanimate heads and pronominal subjects. This will then become the prototype and children will readily interpret such sentences as object relatives, while sentences that deviate from the prototype are harder to comprehend.

In support of this claim, Reali and Christiansen (2007b) found evidence that some object relatives are represented at a highly item-specific level. Using Google counts, the authors showed that there are some highly frequent, lexically specific pronoun-verb combinations in object relatives. For example, the $\mathrm{X}$ who I met is far more frequent than the $\mathrm{X}$ who I distrusted. In a complexity-rating and a self-paced reading task, Englishspeaking adults indicated that doubly-nested object relatives containing highly frequent pronoun-verb combinations were easier than object relatives with less frequent word combinations. Reali and Christiansen take 
this as evidence that parts of object relatives are recognized and accessed as chunks.

Our results cannot address this hypothesis directly because we did not control for the frequency of word co-occurrences. However, our findings suggest that it is not frequent chunks alone that ease the comprehension of object relatives. Our test sentences contained RC subjects and verbs that are usually not found in object relatives in spontaneous speech in the exact same forms. Our corpus study (Kidd et al. 2007) showed that German- and English-speaking children most often use 1st or 2nd person SG pronominal subjects in object relatives. Other corpus findings (Brandt 2006; Fox 1987) showed that object relatives most often contain light or psychological verbs, such as have or like. Looking at the input of an English-speaking child, Brandt (2006) found that 87 percent of the mother's object relatives contained light or psychological verbs. Our test sentences, on the other hand, contained causative verbs, such as chase or bite, and 3rd person SG pronominal subjects. Children still showed better performance with object relatives with inanimate head NPs and 3rd person SG pronominal subjects than object relatives with animate head NPs and full-NP subjects. It is possible that the children would have been even better with object relatives with 1st and 2nd person SG pronominal subjects and light or psychological verbs, but our test sentences were close enough to these most frequent prototypes that they already eased comprehension, which suggests that object relatives are represented at a semi-abstract level. Bybee (2006: 714) claims that "high frequency exemplars serve as the central member of categories" and that these high frequency exemplars have an effect on the semantics of the items that can be used in the slots of a construction. In the current study, the object relatives that contained items that were semantically and formally closer to the items in high frequency exemplars were better comprehended than the object relatives that were semantically and formally further away from the high frequency exemplars. The object relatives with animate head NPs and full-NP subjects caused more difficulty. Our results thus strongly support the assumption that frequent exemplars have an impact on the formation and representation of linguistic categories. The representation of object relatives is presumably grouped around a semiabstract or prototypical schema (cf. Abbot-Smith and Tomasello 2006), such as INANIMATE NP_PRONOUN_-VERB.

Our findings also show that this is already evident in young children. At the age of 3;0, they showed better comprehension of object relatives that are semantically, functionally, and formally close to what they most frequently hear and use as object relatives. Moreover, in the previous study, we did not find any age effects. In the imitation task, the 
English- and German-speaking 4-year-olds performed better than the 3year olds in general, but there were no significant interactions between any of the linguistic manipulations and age, which indicates that children in both age groups are sensitive to the same constraints (Kidd et al. 2007).

Taken together, the corpus findings (e.g., Fox and Thompson 1990; Kidd et al. 2007; Roland et al. 2007), the results from psycholinguistics experiments with adults (e.g., Mak et al. 2002, 2006; Traxler et al. 2002, 2005), the results from the imitation task with children (Kidd et al. 2007), and the comprehension results from the current study strongly support the claim that language production, comprehension, and acquisition mutually constrain each other (e.g., Mac Donald 1999). The types of object relatives that are most frequently used by adults are also the most frequent types in children's spontaneous speech, and both adults and children comprehend these types best. Children and adults can be assumed to perform fine-grained statistical analysis on their input (cf. MacDonald 1999; MacDonald et al. 1994; Reali and Christiansen 2007a; Tomasello 2003) to detect frequency distributions, which are, in turn, born out of discourse pressures. The current study shows that these frequency distributions are part of children's representation of relative-clause structures as they are evident in their comprehension of RCs.

Received 17 December 2007

Revision received 25 August 2008
Max Planck Institute for Evolutionary Anthropology, Leipzig University of Manchester

\section{Appendix}

\section{German test sentences}

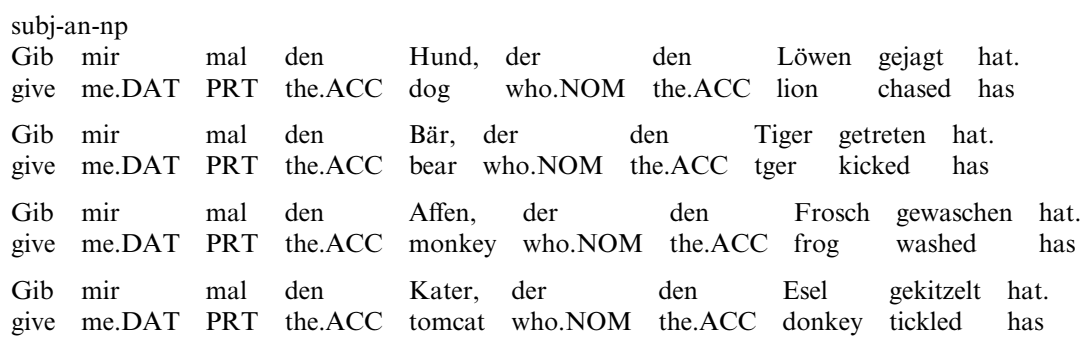


subj-an-pro

\begin{tabular}{|c|c|c|c|c|c|}
\hline $\begin{array}{ll}\text { Gib } & \text { mir } \\
\text { give } & \text { me.DAT }\end{array}$ & $\begin{array}{l}\text { mal } \\
\text { PRT }\end{array}$ & $\begin{array}{l}\text { den } \\
\text { the.ACC }\end{array}$ & $\begin{array}{ll}\text { Löwen, } & \text { der } \\
\text { lion } & \text { who.NOM }\end{array}$ & $\begin{array}{ll}\text { ihn } & \text { eben } \\
\text { him } & \text { just }\end{array}$ & $\begin{array}{l}\text { gejagt } \\
\text { chased }\end{array}$ \\
\hline $\begin{array}{l}\operatorname{mir} \\
\text { me.DAT }\end{array}$ & $\begin{array}{l}\text { mal } \\
\text { PRT }\end{array}$ & $\begin{array}{l}\text { den } \\
\text { the.ACC }\end{array}$ & $\begin{array}{ll}\text { Tiger, } & \text { der } \\
\text { tiger } & \text { who.NOM }\end{array}$ & $\begin{array}{l}\text { gerade } \\
\text { just }\end{array}$ & $\begin{array}{l}\text { eten } \\
\text { ed }\end{array}$ \\
\hline $\begin{array}{l}\operatorname{mir} \\
\text { me.DAT }\end{array}$ & $\begin{array}{l}\text { mal } \\
\text { PRT }\end{array}$ & $\begin{array}{l}\text { den } \\
\text { the.ACC }\end{array}$ & $\begin{array}{ll}\text { Frosch, } & \text { der } \\
\text { frog } & \text { who.NOM }\end{array}$ & $\begin{array}{ll}\text { ihn } & \text { eben } \\
\text { him } & \text { just }\end{array}$ & $\begin{array}{l}\text { gewaschen } \\
\text { washed }\end{array}$ \\
\hline AT & & 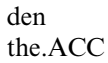 & $\begin{array}{l}\text { der } \\
\text { who.NOM }\end{array}$ & him & tic \\
\hline
\end{tabular}

obj-an-np

Gib mir mal den Hund, den der Löwe geschubst hat. give me.DAT PRT the.ACC dog who.ACC the.NOM lion pushed has

Gib mir mal den Bär, den der Tiger gebissen hat.

give me.DAT PRT the.ACC bear who.ACC the.NOM tiger bitten has

Gib mir mal den Affen, den der Frosch gekämmt hat. give me.DAT PRT the.ACC monkey who.ACC the.NOM frog combed has Gib mir mal den Kater, den der Esel gefüttert hat. give me.DAT PRT the.ACC tomcat who.ACC the.NOM donkey fed has

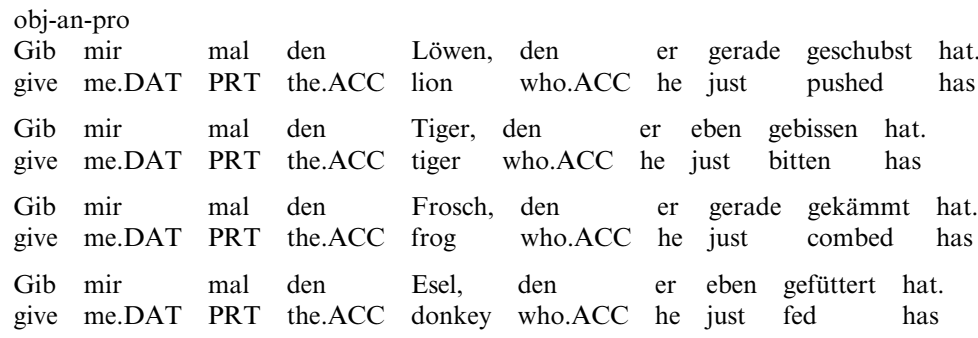

obj-in-np

Gib mir mal den Stift, den der Papa angefasst hat. give me.DAT PRT the.ACC pen that.ACC the.NOM dad touched has

Gib mir mal den Ball, den der Junge getreten hat. give me.DAT PRT the.ACC ball that.ACC the.NOM boy kicked has

Gib mir mal den Pullover, den der Opa gekauft hat. give me.DAT PRT the.ACC sweater that.ACC the.NOM grandpa bought has

Gib mir mal den Kuchen, den onkel geklaut hat. give me.DAT PRT the.ACC cake that.ACC the.NOM uncle stolen has

obj-in-pro

Gib mir mal den Stift, den er eben bewegt hat. give me.DAT PRT the.ACC pen that.ACC he just moved has

Gib mir mal den Ball, den er gerade geworfen hat.

give me.DAT PRT the.ACC ball that.ACC he just trown has

Gib mir mal den Pullover, den er eben gestrickt hat.

give me.DAT PRT the.ACC sweater that.ACC he just knitted has

Gib mir mal den Kuchen, den er gerade gebacken hat. give me.DAT PRT the.ACC cake that.ACC he just baked has 


\section{English test sentences}

subj-an-np

Can you give me the dog that chased the lion.

Can you give me the bear that kicked the tiger.

Can you give me the monkey that washed the frog.

Can you give me the cat that tickled the monkey.

subj-an-pro

Can you give me the lion that just chased him.

Can you give me the tiger that just kicked him.

Can you give me the frog that just washed him.

Can you give me the donkey that just tickled him.

obj-an-np

Can you give me the dog that the lion pushed.

Can you give me the bear that the tiger bit.

Can you give me the monkey that the frog combed.

Can you give me the cat that the donkey fed.

\section{obj-an-pro}

Can you give me the lion that he just pushed.

Can you give me the tiger that he just bit.

Can you give me the frog that he just combed.

Can you give me the donkey that he just fed.

obj-in-np

Can you give me the pen that the dad touched.

Can you give me the ball that the boy kicked.

Can you give me the jumper that the grandpa bought.

Can you give me the cake that the uncle stole.

obj-in-pro

Can you give me the pen that he just moved.

Can you give me the ball that he just threw.

Can you give me the jumper that he just knitted.

Can you give me the cake that he just baked.

\section{References}

Abbot-Smith, Kirsten and Michael Tomasello

2006 Exemplar-learning and schematization in a usage-based account of syntactic acquisition. Linguistic Review 23, 275-290.

Arnon, Inbal

forth- Rethinking child difficulty: The effect of NP type on children's processing of coming relative clauses in Hebrew. Journal of Child Language.

Bates, Elizabeth and Brian MacWhinney

1989 The Cross-Linguistic Study of Sentence Processing. Cambridge: Cambridge University Press.

Bever, Thomas G.

1970 The cognitive basis for linguistic structures. In Hayes, John R. (ed.), Cognition and the Development of Language. New York: Wiley, 279-362. 
Brandt, Silke

2006 Verbs in object relatives. Unpublished manuscript, Max-Planck-Institute for Evolutionary Anthropology, Leipzig.

Brandt, Silke, Holger Diessel and Michael Tomasello

2008 The acquisition of German relative clauses: A case study. Journal of Child Language 35, 325-348.

Bybee, Joan

2006 From usage to grammar: The mind's response to repetition. Language 82, $529-551$.

Chafe, Wallace

1994 Discourse, Consciousness, and Time: The Flow and Displacement of Conscious Experience in Speaking and Writing. Chicago: Chicago University Press.

Chan, Angel, Elaine Lau, Elena Lieven and Michael Tomasello

2007 Cantonese children's acquisition of relative clauses: Cross-linguistic comparisons with English and German children. Paper presented at the Interdisciplinary Approaches to Relative Clauses, Cambridge, UK.

Chan, Angel, Elena Lieven and Michael Tomasello

2009 Children's understanding of the agent-patient relations in the transitive construction: Cross-linguistic comparisons between Cantonese, German and

Clahsen, Harald English. Cognitive Linguistics 20(2), 267-300.

1984 Der Erwerb von Kasusmarkierungen in der deutschen Kindersprache. Linguistische Berichte 89, 1-31.

Clancy, Patricia M., Hyeonjin Lee and Myeong-han Zoh

1986 Processing strategies in the acquisition of relative clauses: Universal principles and language-specific realizations. Cognition 24, 225-262.

Corrêa, Leticia M. S.

1995 An alternative assessment of children's comprehension of relative clauses. Journal of Psycholinguistic Research 24, 183-203.

de Villiers, Jill G., Helen B. Tager-Flusberg, Kenji Hakuta and Michael Cohen

1979 Children's comprehension of relative clauses. Journal of Psycholinguistic Research $8,499-518$.

Diessel, Holger

2004 The Acquisition of Complex Sentences. Cambridge, UK: Cambridge University Press.

Diessel, Holger

2007 The animacy hierarchy and the acquisition of relative clauses. Paper presented at the International Cognitive Linguistics Conference, Krakow.

Diessel, Holger and Michael Tomasello

2000 The development of relative clauses in spontaneous child speech. Cognitive Linguistics 1, 131-151.

Diessel, Holger and Michael Tomasello

2005 A new look at the acquisition of relative clauses. Language 81, 882-906.

Dittmar, Miriam, Kirsten Abbot-Smith, Elena Lieven and Michael Tomasello

2008 German children's comprehension of word order and case marking in causative sentences. Child Development 79, 1152-1167.

Du Bois, John

1987 The discourse basis of ergativity. Language 63, 805-855. 
Eisenberg, Sarita

2002 Interpretation of relative clauses by young children: Another look. Journal of Child Language 29, 177-188.

Fox, Barbara

1987 The noun phrase accessibility hierarchy reinterpreted: Subject primacy or the absolutive hypothesis? Language 63, 856-870.

Fox, Barbara and Sandra A. Thompson

1990 A discourse explanation of the grammar of relative clauses in English conversation. Language 66, 297-317.

Frazier, Lyn and Charles Clifton

1989 Successive cyclicity in the grammar and the parser. Language and Cognitive Processes 4, 93-126.

Friedmann, Naama and Rama Novogrodsky

2004 The acquisition of relative clause comprehension in Hebrew: A study of SLI and normal development. Journal of Child Language 31, 661-681.

Gibson, Edward

1998 Linguistic complexity: Locality of syntactic dependencies. Cognition 68, 176.

Givón, Talmy

1993 English Grammar. A Function-based Introduction. Amsterdam: John Benjamins.

Goldberg, Adele E.

1995 Constructions. A Construction Grammar Approach to Argument Structure. Chicago: The University of Chicago Press.

Goodluck, Helen, Eithne Guilfoyle and Sile Harrington

2006 Merge and binding in child relative clauses: The case of Irish. Journal of Linguistics 42, 629-661.

Goodluck, Helen and Susan Tavakolian

1982 Competence and processing in children's grammar of relative clauses. Cognition 11, 1-27.

Gordon, Peter C., Randall Hendrick and Marcus Johnson

2001 Effects of noun phrase type on sentence complexity. Journal of Memory and Language 51, 97-114.

Hirsh-Pasek, Kathy and Roberta M. Golinkoff

1996 The Origins of Grammar: Evidence from Comprehension. Cambridge, MA: MIT Press.

Hsiao, Franny and Edward Gibson

2003 Processing relative clauses in Chinese. Cognition 90, 3-27.

Kidd, Evan and Edith L. Bavin

2002 English-speaking children's comprehension of relative clauses: Evidence for general-cognitive and language-specific constraints on development. Journal of Psycholinguistic Research 31, 599-617.

Kidd, Evan, Silke Brandt, Elena Lieven and Michael Tomasello

2007 Object relatives made easy: A cross-linguistic comparison of the constraints influencing young children's processing of relative clauses. Language and

Langacker, Ronald W. Cognitive Processes 22, 860-897.

2000 A dynamic usage-based model. In Barlow, Michael and Suzanne Kemmer (eds.), Usage-based models of language. Stanford, CA: CSLI Publications, $1-63$. 
Lehmann, Christian

1984 Der Relativsatz. Tübingen: Gunter Narr Verlag.

Lust, Barbara, Suzanne Flynn and Claire Foley

1996 What we know about what they say: Elicited imitation as a research method. In McDaniel, Dana, Cecile McKee and Helen Smith Cairns (eds.), Methods for Assessing Children's Syntax. Cambridge, MA: MIT Press.

MacDonald, Maryellen C.

1999 Distributional information in language comprehension, production, and acquisition: Three puzzles and a moral. In MacWhinney, Brian (ed.), The Emergence of Language. Mahwah, NJ: Lawrence Erlbaum.

MacDonald, Maryellen C., Neal J. Pearlmutter and Mark S. Seidenberg

1994 The lexical nature of syntactic ambiguity resolution. Psychological Review 101, 676-703.

Mak, Willem M., Wietske Vonk and Herbert Schriefers

2002 The influence of animacy on relative clause processing. Journal of Memory and Language 47, 50-68.

2006 Animacy in processing relative clauses: The hikers that rocks crush. Journal of Memory and Language 54, 466-490.

Potter, Mary C. and Linda Lombardi

1990 Regeneration in the short-term recall of sentences. Journal of Memory and Language 29, 633-654.

Potter, Mary C. and Linda Lombardi

1998 Syntactic priming in immediate recall of sentences. Journal of Memory and Language 38, 265-282.

Reali, Florencia and Morten H. Christiansen

2007a Processing of relative clauses is made easier by frequency of occurrence. Journal of Memory and Language 57, 1-23.

Reali, Florencia and Morten H. Christiansen

2007b Word chunk frequencies affect the processing of pronominal object-relative clauses. The Quarterly Journal of Experimental Psychology 60, 161-170.

Roland, Douglas, Frederic Dick and Jeffrey L. Elman

2007 Frequency of basic English grammatical structures: A corpus analysis. Journal of Memory and Language 57, 348-379.

Sachs, Jacqueline S.

1967 Recognition memory for syntactic and semantic aspects of connected discourse. Perception and Psychophysics 2, 437-442.

Sheldon, Amy

1974 The role of parallel function in the acquisition of relative clauses in English.

Journal of Verbal Learning and Verbal Behavior 13, 272-281.

Szagun, Gisela

2004 Learning by ear: On the acquisition of case and gender marking by Germanspeaking children with normal hearing and with cochlear implants. Journal

Tavakolian, Susan of Child Language 31, 1-30.

1981 The conjoined clause analysis of relative clauses. In Tavakolian, Susan (ed.), Language Acquisition and Linguistic Theory. Cambridge, MA: MIT Press.

Tomasello, Michael

2003 Constructing a Language. A Usage-based Theory of Language Acquisition. Cambridge, MA: Harvard University Press. 
Traxler, Matthew J., Robin K. Morris and Rachel E. Seely

2002 Processing subject and object relative clauses: Evidence from eye movements. Journal of Memory and Language 47, 69-90.

Traxler, Matthew J., Rihana S. Williams, Shelley A. Blozis and Robin K. Morris

2005 Working memory, animacy, and verb class in the processing of relative clauses. Journal of Memory and Language 53, 204-224.

Warren, Tessa and Edward Gibson

2002 The influence of referential processing on sentence complexity. Cognition 85, $79-112$.

Warren, Tessa and Edward Gibson

2005 Effects of NP type in reading cleft sentences in English. Language and Cognitive Processes 20, 751-767. 